\title{
Biology and Biometrics of Oriental Fruit Fly, Bactrocera dorsalis (Hendel) (Diptera: Tephritidae) on Custard Apple, Annona squamosa L.
}

\author{
H. Sunil Naik ${ }^{1 *}$, K.S. Jagadeesh ${ }^{1}$ and B.S. Basavaraju ${ }^{2}$ \\ ${ }^{1}$ Department of Entomology, University of Agricultural Sciences, GKVK, \\ Bangalore, Karnataka, India \\ ${ }^{2}$ Department of Entomology, College of agriculture, Hassan, University of Agricultural Sciences, \\ GKVK, Bangalore, Karnataka, India \\ *Corresponding author
}

\begin{tabular}{|c|c|}
\hline & A B S T R A C T \\
\hline $\begin{array}{l}\text { Ke y w o r d s } \\
\text { Bactrocera } \\
\text { dorsalis, Biology, } \\
\text { Biometrics, Custard } \\
\text { apple. }\end{array}$ & $\begin{array}{l}\text { The oriental fruit fly Bactrocera dorsalis (Hendel) is a very serious pest of fruit crop or } \\
\text { trees, globally causing considerable economic losses. The present investigation on biology } \\
\text { and biometrics of } B \text {. dorsalis was studied on custard apple under laboratory conditions at } \\
\text { Department of Agricultural Entomology, Gandhi Krishi Vignana Kendra (GKVK), } \\
\text { University of Agricultural Sciences, Bengaluru, Karnataka during 2015-16. During the } \\
\text { period of investigation the mean maximum and minimum temperatures recorded was }\end{array}$ \\
\hline Article Info & experimental results revealed that average length and breadth of egg, full-grown maggots \\
\hline $\begin{array}{l}\text { Accepted: } \\
28 \text { October } 2017 \\
\text { Available Online: } \\
10 \text { December } 2017\end{array}$ & $\begin{array}{l}\text { and pupae were about } 1.36 \pm 0.12 \mathrm{~mm} \text { and } 0.25 \pm 0.13 \mathrm{~mm}, 8.18 \pm 0.84 \text { and } 2.25 \pm 0.70 \mathrm{~mm} \text {, } \\
4.08 \pm 0.58 \mathrm{~mm} \text { and } 1.82 \pm 0.69 \mathrm{~mm} \text { respectively and length of adult flies measured about } \\
6.20 \pm 0.73 \text { and } 8.13 \pm 0.69 \mathrm{~mm} \text { in male and female respectively. The biological study } \\
\text { revealed that developmental period from immature to adult stages is varied from } 18 \text { to } 23 \\
\text { days with the mean fecundity of } 12.4 \pm 2.54 \text { eggs/day. }\end{array}$ \\
\hline
\end{tabular}

\section{Introduction}

The oriental fruit fly Bactrocera dorsalis (Hendel), first reported in Taiwan Island, is one of the most destructive pests of fruits and vegetables around the world, causing huge economic losses each year (Wei et al., 2017) and is a serious pest on a wide range of fruit crops in the Indian subcontinent (Kamala Jayanthi et al., 2011). It is endemic to Southeast Asia, but has also been introduced to various region of the world and became threats to the wide range of cultivated and wild fruits (Drew and Raghu, 2002). David and Ramani (2011) reported 325 species, of which 243 families and 79 genera are from
India alone. B. dorsalisis reported to cause $100.0,87.0,78.0$ and $61.0 \%$ fruit damage in rainy season on guava, mango, peach and pear respectively (Sharma et al., 2011), whereas Singh (2010) reported significant losses in Kinnow due to fruit flies. The damage on crops caused by oriental fruit flies resulted from oviposition in fruit, feeding by the maggots and decaying of tissue by invading secondary microorganisms that leads to fruit drop.

Custard apple, Annona squamosa L. (Family: Annonaceae), is a lowland or marginally 
subtropical crop being cultivated throughout the tropics and warmer subtropics for its edible fruit. This crop is being attacked by a number of pests that feed on its roots, stems, leaves and fruits (Gabriel, 1975). Presently fruit fly is attaining a considerable pest status and causing up to 25 per cent yield loss in the custard apple orchard and gaining the economic importance under commercial cultivation. Fruit fly menace is difficult to manage because of the fact that these are polyphagous, multivoltine, adults with high mobility, fecundity and all the developmental stages are unexposed (Sharma et al., 2011). Hence in order to prevent its spread and reduce damage, great efforts have been made to clarify its ecological and physiological adaptation and to develop control methods (Wei et al., 2017). So to know the advancement of damage and distribution in the population of fruit fly on custard apple, there is enormous scope for gaining the knowledge of biology and biometrics of $B$. dorsalis on Annona species, which is being commercialized in the recent days so for better marketability there is essential in developing efficient management strategy which can prevent wasteful costly as well as hazardous insecticide usage. Keeping in view of the precedent perspectives, the present investigation on study of the biology and biometrics of $B$. dorsalis on custard apple under laboratory condition was undertaken with the precise experimental set up.

\section{Materials and Methods}

\section{Developmental studies}

Experiment was conducted on custard apple under laboratory conditions at Department of Agricultural Entomology, Gandhi Krishi Vignana Kendra (GKVK), University of Agricultural Sciences, Bengaluru, Karnataka during 2015-16 with the following methodologies. The biology of $B$. dorsalis was studied under suitable laboratory conditions (mean maximum and minimum temperatures recorded were $28.5^{\circ} \mathrm{C}$ and $19.1^{\circ} \mathrm{C}$ respectively, with mean relative humidity of 71.3 per cent). Twenty infested custard apple fruits have been collected from the orchard. The fruits were kept individually rearing cages $(35 \mathrm{~cm} \times 30 \mathrm{~cm} \times 35 \mathrm{~cm})$, provided with plastic tray containing $5 \mathrm{~cm}$ thick layer of sieved sand as source for pupation and covered with muslin cloth for the observation of developmental studies of fruit flies. Fruits were dissected few days after collection for counting the number of maggots present in each fruit and allowed for the pupation. Pupae were collected in the petridish and kept in the separate cages for adult emergence and freshly emerged adults (males and females) were provided with protinex powder, honey solution and water as adult diet and the fruit fly species emerged from infested custard apple fruits were identified from Insect Biosystematics Laboratory, Department of Entomology, UAS, GKVK, Bengaluru. 10 pairs of male and female flies were kept separately in the vials for mating process and further used to study the life cycle studies of $B$. dorsalis on custard apple fruit.

Gravid females were kept in the cage provided with a piece of fresh and tender fruits of custard apple, water and honey solution for egg laying. The eggs were detected by excavating the fruit just below the oviposition puncture through microscopic observations and same were recorded randomly from ten samples (eggs) on five individual fruits. The eggs were transferred in the Petridish containing pulp. Freshly hatched first instar maggots were further transferred to fresh fruit and maggot duration was recorded for the same. Last instar maggots were transferred to the plastic tray containing the sand for pupation, same were collected in the petridish and kept in the separate cages for 
adult emergence. The developmental duration of all ate stages were recorded and subjected to the statistical analysis.

\section{Morphometric studies}

Few individuals of maggots, pupae and adults were collected and preserved in the 70 per cent ethyl alcohol for taking morphometric measurements. Morphometric parameters like length and width of maggots, pupae and adults were recorded by taking 10 individuals. Weight and wing expanse of 10 male and female adult fruit flies was also recorded separately. The measurements were made by using ocular micrometer after standardizing it with stage micrometer at 40x magnification. The data was tabulated for drawing further interpretation and presented below.

\section{Results and Discussion}

\section{Biology and morphometric of different life} stages of oriental fruit fly $\boldsymbol{B}$. dorsalis

\section{Eggs}

The eggs of $B$. dorsalis were elliptical, smooth, elongated, slightly curved and tapering at one end. The posterior end is broadly rounded and the anterior end was found to be pointed and shiny white in colour and turned dark brown colour as they nearer to the hatching. Morphometric observations revealed that the eggs measured about $1.36 \pm 0.12 \mathrm{~mm}$ in length and $0.25 \pm 0.13 \mathrm{~mm}$ in width. These findings are in close agreement with the results of Singh et al., (2010), who observed that the mean length and width of egg was $1.30 \pm 0.07$ and $0.24 \pm 0.04 \mathrm{~mm}$, respectively (Table 1) and even the mean incubation period was $1.50 \pm 0.48$ days, which is in close agreement with the observations made by Singh et al., (2010), who observed an incubation period of $1.3 \pm 0.41$ days (Table 2).

\section{Maggots}

The matured maggots were cylindrical, apodous, frugivorous with an elongated body, pointed anteriorly or cephalic end and blunt posteriorly. The black coloured mouth hooks were retractile and extended outside the body at the time of feeding. The mean maggot period was $8.50 \pm 0.84$ days (Table 2), the freshly hatched maggot was pale white in colour with translucent body and later instars are turn to brownish yellow in colour. All these findings are in line with reports of Kalia and Yadav (2015), who recorded the larval period of $B$. dorsalis as $7.5 \pm 0.16$ and $8.4 \pm 0.33$ days on mango and sapota, respectively.

The mean body length and width of the freshly hatched maggot and full grown maggot was $2.87 \pm 0.74$ and $0.40 \pm 0.18$ and $8.18 \pm 0.84$ to $2.25 \pm 0.70 \mathrm{~mm}$ respectively (Table 1). The present observations are in corroborated with the earlier findings of Singh et al., (2010), who reported $3.8 \pm 0.074 \mathrm{~mm} \times 0.55 \pm 0.10 \mathrm{~mm}$ and $8.02 \pm 1.02$ $\mathrm{mm} \times 1.55 \pm 0.17 \mathrm{~mm}$ for fresh and full grown maggots respectively.

\section{Pupa}

The pupation of $B$. dorsalis occurs in the moist sand. The pupae were segmented, barrel shaped or cylindrical and yellowish white to deep brownish yellow when freshly formed. Later on, the colour changed into light brown to brownish grey with 11 distinct segments. Morphometric measurements of pupae recorded was about $4.08 \pm 0.5 \mathrm{~mm}$ in length and $1.82 \pm 0.69 \mathrm{~mm}$ in width (Table 1) and these results are in accordance with Vishva (2011), who recorded $4.60 \mathrm{~mm}$ length and $2.01 \mathrm{~mm}$ width in B. cucurbitae under laboratory condition, when reared on gherkins and the pupal period lasted for $12.10 \pm 1.79$ days (Table 2). The present findings are in accordance with that of Kalia and Yadav 
(2015), who reported the mean pupal period of $B$. dorsalis as $10.4 \pm 0.30$ and $11.7 \pm 0.15$ days on papaya and banana respectively.

\section{Adult}

The adult fruit flies are noticeably larger than house fly, black to orange brown in colour and having a typical $\mathrm{T}$ shaped marking on the abdomen. The wings contain fuscous shedding (wing band) on the outer margin.

On the apical margin of wing greyish brown patches were noted with black bands on the radio-medial veins and these findings are in accordance with the morphological descriptions reported by Kalia and Yadav (2015).

\section{Male}

In adult male, the abdomen was blunt and smaller in size than that of the female. The length and breadth (wing expanse) of the male adult varied from 4.91 to $7.23 \mathrm{~mm}$ (mean \pm S.D $=6.20 \pm 0.73$ ) and 10.10 to $12.65 \mathrm{~mm}$ (mean \pm S.D. $=11.50 \pm 1.01)$ respectively. The longevity of male was $52.4 \pm 8.74$ days and allthese findings are similar to that of Singh $e t$ al., (2010) in case of Bactrocera tau on Cucurbita maxima and Lasker (2013) in case of B. cucurbitae on pumpkin.

Table.1 Morphometric measurements of different life stages of B. dorsalis on custard apple

\begin{tabular}{|c|c|c|c|c|c|c|c|}
\hline \multirow{2}{*}{$\begin{array}{l}\text { Sl. } \\
\text { No. }\end{array}$} & \multirow{2}{*}{ Insect stages } & \multicolumn{3}{|c|}{ Length(mm) } & \multicolumn{3}{|c|}{ Width(mm) } \\
\hline & & \multicolumn{2}{|c|}{ Range } & Mean \pm SD & \multicolumn{2}{|c|}{ Range } & Mean \pm SD \\
\hline 1 & Egg & 0.85 & 2.09 & $1.36 \pm 0.38$ & 0.08 & 1.21 & $0.25 \pm 0.13$ \\
\hline 2 & Larva & 2.76 & 8.35 & $6.07 \pm 1.97$ & 0.62 & 3.18 & $1.75 \pm 0.89$ \\
\hline 3 & Pupa & 2.95 & 4.94 & $4.08 \pm 0.58$ & 1.18 & 2.67 & $1.84 \pm 0.48$ \\
\hline 4 & Male & 4.91 & 7.23 & $6.20 \pm 0.73$ & - & - & - \\
\hline 5 & Female & 6.7 & 8.98 & $8.13 \pm 0.69$ & - & - & - \\
\hline
\end{tabular}

Note: SD: Standard deviation; $n=10$

Table.2 Duration of different life stages of B. dorsalis reared on custard apple

\begin{tabular}{|c|c|c|c|}
\hline \multirow{2}{*}{ Stage of Life cycle } & \multicolumn{3}{|c|}{ Duration (in days) } \\
\cline { 2 - 4 } & Min & Max & Mean \pm SD \\
\hline Incubation period & 1 & 2.3 & $1.50 \pm 0.48$ \\
\hline Larval duration & 7 & 10 & $8.50 \pm 0.84$ \\
\hline Pupal period & 9 & 14 & $12.10 \pm 1.79$ \\
\hline Pre-oviposition period & 10 & 14 & $12.10 \pm 1.28$ \\
\hline Fecundity & 267 & 436 & $371.9 \pm 60.78$ \\
\hline Female adult longevity & 54 & 86 & $70.50 \pm 12.10$ \\
\hline Male adult longevity & 39 & 62 & $52.40 \pm 6.70$ \\
\hline Total life span & 18 & 23 & $20.30 \pm 0.82$ \\
\hline
\end{tabular}

Note: SD: Standard deviation; $n=10$

\section{Female}

Adult females were easily distinguishable by the presence of tapering abdomen extending into an ovipositor and comparatively larger than the males. The length and breadth (wing expanse) of the female adult was found to vary from 6.70 to $8.98 \mathrm{~mm}$ (mean $\pm \mathrm{S} . \mathrm{D}=$ 
$8.13 \pm 0.69)$ and 12.20 to $16.50 \mathrm{~mm}$ (mean \pm S.D. $=14.00 \pm 1.69)$ respectively. Thelongevity of female was $64.6 \pm 9.72$ days. These findings were similar to that of reports of Singh et al., (2010) in B. tau on C. maxima and Lasker (2013) on B. cucurbitae on pumpkin.

\section{Reproduction}

The freshly emerged adults were fed for few days with proteinex mixture, water and honey as adult diet. The pre-oviposition period was observed between 10 to 14 days, with a mean duration of $12.1 \pm 1.28$ days. These findings are in agreement with the findings of Singh $e t$ al., (2010).

\section{Fecundity}

It was recorded that each female laid a mean of $12.4 \pm 2.54$ eggs/day with a mean total fecundity of $371.9 \pm 60.78$ eggs/female during its life cycle. Contrary to the present studies, Singh et al., (2010) reported that each female laid a 16.01 \pm 12.01 eggs/day with mean fecundity of $464.6 \pm 67.98$ eggs/female when reared on Cucurbita maxima. These differences could be attributed to the difference in the season and geographical location involved in these two different studies

\section{Total developmental period}

The total life cycle from egg to adult emergence recorded 18 to 23 days, with a mean of $20.3 \pm 2.82$ days in the present study. These results are in confirmation with those of Kalia and Yadav (2015), who reported a total developmental period of $20.3 \pm 0.44$ and $21.6 \pm 0.88$ days on banana and sapota by $B$. dorsalis respectively.

Results of the present study with regard to duration of different life stages of oriental fruit fly are in agreement with Kalia (1992),
Singh et al., (2010), Vishva (2011), Sandeep singh and Sharma (2013), Mir et al., (2014), Kalia and Yadav (2015).

Custard apple is being commercializing in the subtropical and tropical climatic condition recently, there is a need for understanding the production and protection aspects of the crop. In India, the area and production of Annona species is considerably increasing in the recent years, although it is growing as a marginal crop, but due to its pharmaceutical significance recently gaining importance.

So there is a need for accounting the plant protection measures to ensure the better production of the crop, hence as the fruit fly, $B$. dorsalis is being threats to the crop in the recent days, so to understand the biology of $B$. dorsalis on $A$. squamosa we undertaken the laboratory study and results revealed that the total developmental period was 18 to 23 days, with a mean of $20.3 \pm 2.82$ days and other developmental parameters were presented in the results and discussion section and by knowing the life cycle of a pest we can exploit these findings in the better field management of an pest.

\section{Acknowledgement}

The authors are thankful to Department of Agricultural Entomology, UAS, GKVK, Bengaluru and all the faculty for providing necessary facilities for conducting the study and valuable suggestions during the course of investigation.

\section{References}

David, K. J., and Ramani, S.2011. An illustrated key to fruit flies (Diptera: Tephritidae) from peninsular India and Andaman and Nicobar Islands. Zootaxa. 3021: 1-31. 
Drew, R.A.I., and Raghu, S. 2002. The fruit fly fauna (Diptera: Tephritidae: Dacinae) of the rainforest habitat of the Western Ghats, India, The Raffles Bulletin of Zoology. 50(2):327-352.

Gabriel, B. P., 1975. Insects and mites injurious to Philippine crop plants. Department of Entomology at Los Banos College Laguna, Mimeographed, pp250.

Kalia, V. K.,and Yadav, B. 2005. Costeffective mass rearing of the oriental fruit fly, Bactrocera dorsalis (Hendel) round the year. International Research Journal of Natural and Applied Sciences.2: 6 .

Kalia, V., 1992. Bionomics of fruit fly, Dacus dorsalis on some cultivars of mango and guava. Bulletin of Entomology.33: 79-87.

Laskar., 2013. Biology and biometrics of melon fruit fly, Bactrocera cucurbitae (Coq.) on bitter gourd, Momordica charantia L. and pumpkin, Cucurbita pepo L.,Current Biotica.7(1): 51-59.

Mir, S. H.,Dar, S. A., Mir, G. M., and Ahmad, S. B. 2014. Biology of Bactrocera cucurbitae (Diptera: Tephritidae) on cucumber.

Florida Entomologist.97(2):753-758.

Kamala Jayanthi, P.D., Abraham Verghese and Sreekanth, P.D. 2011. Predicting the oriental fruit fly Bactrocera dorsalis (Diptera: Tephritidae) trap catch using artificial neural networks: a case study. International Journal of Tropical Insect Science. 31 (4): 205211.
Ramani, S., 1997. Biosystematic studies on fruit flies (Diptera: Tephritidae) with special reference to the fauna of Karnataka and Andaman and Nicobar, India. Ph.D. Thesis, University of Agricultural Sciences, Bangalore, India.

Sandeep Singh and Sharma, D.R., 2013. Biology and morphometry of Bactrocera dorsalis and Bactrocera zonata on different fruit crops.147, Indian Journal of Agriculture Science. 83 (12):1423-25.

Sharma, D. R, Singh, S., and Aulakh, P. S. 2011. Management of Fruit Flies in Fruit Crops. Department of Horticulture, Punjab Agricultural University, Ludhiana.

Singh, S. K., Kumar, D., and Ramamurthy, V. V. 2010. Biology of Bactrocera (Zeugodavus) tau (Walker) (Diptera: Tephritidae). Entomological Research.40: 259-263.

Vishva, N.S., 2011. Biology, Behaviour and Management of Melon fly, Bactrocera (Zeugodaccus) cucurbitae (Coquillet) (Diptera: Tephritidae). M.Sc. (Agri), Thesis, University of Agricultural Sciences, Bangalore, India.

Wei, D., Dou, W., Jiang, M., and Wang, J. 2017. Oriental Fruit Fly Bactrocera dorsalis (Hendel). In: Wan F., Jiang M., Zhan A. (Eds), Biological Invasions and Its Management in China. Invading Nature - Springer Series in Invasion Ecology, vol 11. Springer, Dordrecht.

\section{How to cite this article:}

Sunil Naik, H., K.S. Jagadeesh and Basavaraju, B.S. 2017. Biology and Biometrics of Oriental Fruit Fly, Bactrocera dorsalis (Hendel) (Diptera: Tephritidae) on Custard Apple, Annona squamosa L. Int.J.Curr.Microbiol.App.Sci. 6(12): 3859-3864.

doi: https://doi.org/10.20546/ijcmas.2017.612.445 